\title{
Optical coherence tomography imaging after successful percutaneous coronary intervention treatment of coronary perforation following bioabsorbable vascular scaffold implantation: Consecutive ping-pong and child-in-mother techniques
}

Carlos Cortés ${ }^{1}$, Ignacio J. Amat-Santos ${ }^{1}$, Milosz Jaguszewski ${ }^{2,3}$, Paol Rojas ${ }^{1}$, L. Renier Gonçalves ${ }^{1}$, Juan Luis Gutiérrez-Chico ${ }^{2,3}$, J. Alberto San Román ${ }^{1}$

${ }^{1}$ Hospital Clínico Universitario de Valladolid, ICICOR, Spain

${ }^{2}$ Klinikum Frankfurt an der Oder, Interventional Cardiology, Germany

${ }^{3}$ Institute of Cardiovascular Translational Research of Atlantic, Berlin, Germany

\begin{abstract}
A 68-year-old male, former smoker, with dyslipidemia, and 7-year history of stable angina was admitted to our center due to symptom progression and positive treadmill test under optimal medical treatment with aspirin, beta-blockers, and highdose statins. Transradial coronary angiography evidenced a chronic total occlusion (CTO) of the proximal left anterior descending artery (LAD), severe stenosis of the proximal left circumflex artery (LCx), and a dominant right coronary artery with collateral flow to the mid and distal bed of the LAD (Rentrop 3, CC 2). Left ventricular (LV)-angiography evidenced LV normal size and function.

LCx stenosis was successfully treated with zotarolimus-eluting stent (Resolute Onyx, Minnesota, Minneapolis, USA) and ad hoc revascularization of the LAD-CTO was attempted by a hybrid antegrade-retrograde approach (Fig. 1A). Successful recanalization of the LAD was achieved by means of hydrophilic high-torque guidewire (Progress 80, Abbott, Vascular Abbott Park, Illinois, USA) supported by a microcatheter (Finecross, Terumo corporation, Tokyo, Japan). Subsequent predilation of the entire occluded segment was performed using $2.0 \times 20 \mathrm{~mm}$ balloon (14 atm). Adequate antegrade flow was evidenced at this point of the procedure (Fig. 1B) and, thus,
\end{abstract}

a $3.0 \times 28 \mathrm{~mm}$ bioresorbable vascular scaffold (BVS, Absorb $^{\circledR}$, Abbott Vascular, Santa Clara, CA, USA) was implanted at $14 \mathrm{~atm}$. Immediate angiography evidenced a massive coronary perforation (Ellis type III, Fig. 1C) with tamponade. Balloon inflation at the perforation site succeeded to stop the bleeding and hemodynamic stability was restored after emergent pericardiocentesis. To fix the perforation while preventing the pericardial bleeding a dual catheter (ping-pong) technique was performed: the guiding catheter was slightly removed, while anchored with the inflated balloon, allowing intubation with a second guiding catheter. Then a second wire was advanced to the distal LAD requiring transient deflation of the hemostatic balloon (Fig. 1D). Delivery of a pericardium-covered stent (JOSTENT, Graftmaster, Abbott, Vascular Abbott Park, Illinois, USA) failed, so the implantation of a meshcovered $3.0 \times 23 \mathrm{~mm}$ M-Guard stent (M-Guard, InspireMD, TelAviv, Israel) was decided, following the experience previously reported of cases, in an attempt to expedite the consolidation of the clot, but it was unfruitful. Hence, a child-in-mother monorail guiding catheter extension (GuideLiner, Vascular Solutions, Inc. Minneapolis, Minnesota, USA) was used to facilitate the $3.0 \times 25 \mathrm{~mm}$ JOSTENT delivery. The leakage was successfully

Address for correspondence: Ignacio J. Amat-Santos, MD, Hospital Clínico Universitario de Valladolid C/Ramón y Cajal 3, 47005 Valladolid, Spain, e-mail: ijamat@gmail.com 


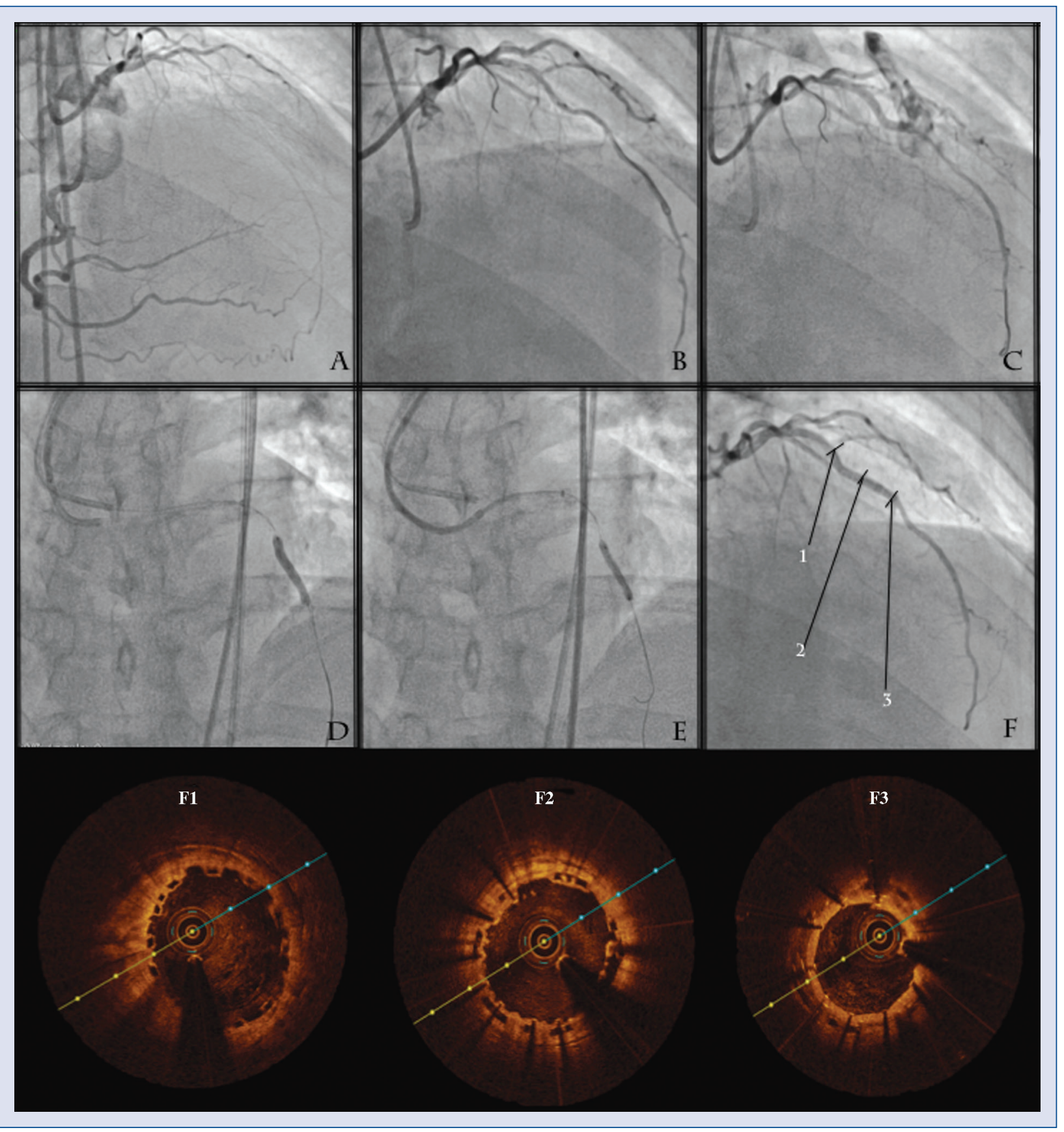

Figure 1. A. Dual catheter contrast injection showing proximal occlusion of the left anterior descending artery (LAD); B. Recanalization of the LAD after balloon predilation; C. Ellis type III coronary perforation of the mid-LAD after bioabsorbable vascular scaffold implantation; D. Mesh-coverd stent delivered to the perforation site through second guiding catheter (ping-pong technique); E. Pericardium-covered stent delivered to the perforation site (within previous mesh-covered stent) with increased back up through child-in-mother technique; F. Successful percutaneous correction of the coronary perforation and adequate aposition of the struts as evaluated by optical coherence tomography (OCT); F1. OCT image shows proximal segment of the Absorb; F2. OCT shows overlap of Absorb and M-Guard stent; F3. OCT shows overlap of the M-Guard and pericardium-covered stent.

sealed (Fig. 1E) and the patient was transferred to the coronary care unit. In this case we did not use protamine because it can complicate the pericardial drainage due to clotting and haematoma, and because hemodynamic stability was restored after pericardial drainage and balloon inflation.

Five days later the LAD was angiographically patent. Optical coherence tomography (OCT) 
showed optimal expansion of Absorb (Fig. 1F1), overlap of Absorb ${ }^{\circledR}$ and M-Guard stent (Fig. 1F2) and the Absorb ${ }^{\circledast}$, M-Guard and Pericardium-covered stents overimposed in 3 layers (Fig. 1F3). At the $7^{\text {th }}$ day patient was discharged. Twelve months of dual antiplatelet therapy was recommended at discharge but close clinical follow up was scheduled, as well as OCT after 12-months follow-up.

Although both, coronary perforation after BVS and the use of these devices in CTOs, have been previously reported [1], to the best of our knowledge, there are no data presenting a case of CTO treated with Absorb $^{\circledR}$ and complicated with coronary rupture. Indeed, percutaneous coronary intervention for CTOs is an independent risk factor for coronary perforation and accounts for $2.4 \%$ of recanalization procedures [2] being more frequent as compared to non-CTO procedures [3]. Also, as a matter of fact, albeit the use of Absorb ${ }^{\circledR}$ has been demonstrated safe and useful in several scenarios, the higher width of the struts $(150 \mu \mathrm{m}$ as compared to $<100 \mu \mathrm{m}$ of metallic stents) could potentially hinder the distal delivery of covered stents in case of complication.

Adequate percutaneous management of perforations includes, as a first step, in nearly all cases, prolonged balloon inflation to diminish active bleeding and to assure hemodynamic stability. In some patients this strategy can be enough but sometimes covered stent implantation is required to achieve complete sealing of the perforation [4]. The development of covered stents represents a paradigm shift in the management of this complication, arising as an actual alternative to cardiac surgery [5]. Nevertheless, deployment of such stents can be still challenging [6], so manoeuvers to increase the back-up can be crucial to succeed. The dual-catheter technique, also called ping-pong technique, was firstly described for the treatment of coronary perforation in 2003 [7]. This is a very useful strategy that can help to minimize coronary bleeding after perforation and during reparation of the damage, with and increasing use in many centres [8]. However, in some cases this strategy may not be enough due to reduced back-up of the guiding catheter. In that scenario, other techniques as anchoring balloon in a side branch (ideally, using 7-8 Fr catheters) or the child-in- -mother technique as in the herein reported case can improve deliverability. This technique is an alternative to single-catheter deep intubation and nowadays it can be performed with specific devices including Guideliner (Vascular Solutions Inc.) or the Guidezila (Boston Scientific Corporation) [9]. It has been useful in complex cases [10] and can yield excellent results, particularly in emergent situations requiring covered stent implantation.

In summary, coronary perforation is a lifethreatening complication that can occur during BVS implantation in CTOs that can be optimally treated by delivery of a covered stent to the perforation site. Dedicated techniques, like ping-pong or child-in-mother, might be required to solve the acute situation and to improve the deliverability of these devices.

\section{Conflict of interests: None declared}

\section{References}

1. Gomez-Lara J, Teruel L, Romaguera R et al. Coronary perforation after bioresorbable vascular scaffold implantation. Eurointervention, 2015; 10: e1-e2.

2. Vishal P, Tesfalder TM, Mogabgab O et al. Clinical, angiographic and procedural of preciprocedural complications during chronic total occlusion percutaneous coronary intervention. Invasive Cardiol, 2014; 23: 100-105.

3. Shimony A, Zahger D, Van Straten M et al. Incidence, risk factors, management and outcomes os coronary artery perforation during percutaneus coronary intervention. Am J Cardiol, 2009; 104: 1674-1677.

4. Al-Lamee R, Ielasi A, Latib A et al. Incidence, predictors, management, immediate and long-term outcomes following grade III coronary perforation. J Am Coll Cardiol Intv, 2011; 4: 87-95.

5. Briguori C, Nishida T, Anzuini A, Di Mario C, Grube E, Colombo A. Emergency polytetrafluoroethylene-covered stent implantation to treat coronary ruptures. Circulation, 2000; 102: 3028-3031.

6. Chen S, Lotan C, Jaffe R et al. Pericardial covered stent coronary perforations. Catheter Cardiovasc Interv, 2015; 86: E28-E31.

7. Silver KH, Brauman WB, Berkovitz KE. Dual-catheter covered stenting: A novel aproach to the treatment of coronary artery perforations. J Invasive Cardiol, 2003; 15: 348-350.

8. Ben-Gal Y, Weisz G, Collins MB et al. Dual catheter technique for the treatment of severe coronary artery perforations. Catheter Cardiovasc Interv, 2010; 75: 708-712.

9. Takahashi $\mathrm{S}$, Saito $\mathrm{S}$, Tanaka $\mathrm{S}$ et al. New method to increase a backup support of a 6 french guiding coronary catheter. Catheter Cardiovasc Interv, 2004; 63: 452-456.

10. Mamas M, Fath-Ordoubadi F, Fraser D. Distal stent delivery with guideliner catheter: First in man experience. Catheter Cardiovasc Interv, 2010; 76: 102-111. 